MaPan : Jurnal Matematika dan Pembelajaran

p-ISSN: 2354-6883 ; e-ISSN: 2581-172X

Volume 5, No 2, December 2017 (293-301)

DOI: https://doi.org/10.24252/mapan.v5n2a10

\title{
PENGARUH PENDEKATAN PEMBELAJARAN MATEMATIKA REALISTIK INDONESIA (PMRI) TERHADAP KEMAMPUAN PEMECAHAN MASALAH MATEMATIKA SISWA KELAS VII SMP NEGERI 2 SRANDAKAN
}

\author{
Siti Oftiana1), Abdul Aziz Saefudin²) \\ 1,2Pendidikan Matematika FKIP Universitas PGRI Yogyakarta \\ 1,2Kampus: Jalan PGRI 1 Sonosewu No. 117, Ngestiharjo, Kasihan, Yogyakarta \\ E-mail: sitioftiana78@gmail.com¹), aziz@upy.ac.id²)
}

\begin{abstract}
Abstrak:
Penelitian ini bertujuan untuk mengetahui ada tidaknya pengaruh pendekatan Pembelajaran Matematika Realistik Indonesia (PMRI) terhadap kemampuan pemecahan masalah matematika siswa kelas VII di SMP Neg. 2 Srandakan. Penelitian ini dilakukan di SMP Neg. 2 Srandakan. Penelitian ini adalah penelitian eksperimen dengan menggunakan metode Quasi Eksperimental Design dan desain penelitian Nonequivalent Posttes-Only Control Group Design. Dalam penelitian ini teknik sampling yang digunakan adalah simple random sampling. Dari enam kelas populasi, diambil dua kelas sampel yaitu kelas VII C sebagai kelas eksperimen dengan diberi perlakuan pendekatan PMRI dan kelas VII E sebagai kelas kontrol dengan pembelajaran langsung. Analisis data dalam penelitian menggunakan teknik analisis statistik deskriptif dan analisis statistik inferensial yang dibagi dalam dua tahap, yaitu tahap awal yang merupakan tahap pemadanan sampel dan tahap akhir, yang merupakan tahap analisis data untuk menguji hipotesis penelitian. Hasil uji normalitas nilai posttes kelas eksperimen diperoleh nilai sig. 0,088 >0,05 dan pada kelas kontrol diperoleh nilai sig. 0,062 >0,05, sehingga nilai posttes kedua kelas berdistribusi normal. Uji homogenitas nilai posttes diperoleh nilai sig. 0,584 $>0,05$, sehingga variansi kedua kedua kelas homogen. Selanjutnya, karena uji prasyarat terpenuhi maka dilakukan analisis statistika inferensial, yaitu uji t. Hasil perhitungan uji t dengan menggunakan uji Independent-Samples $T$ Tes adalah $t_{\text {hitung }}>t_{\text {tabel }}$ yaitu 3,094 $>1,67469$ dengan sig. 0,003, maka dapat disimpulkan bahwa pendekatan Pembelajaran Matematika Realistik Indonesia (PMRI) berpengaruh terhadap kemampuan pemecahan masalah matematika siswa. Hal ini dapat dilihat dari hasil rata-rata nilai posttes kelas eksperimen yaitu 77,86 lebih tinggi dari kelas kontrol yaitu 69,81.
\end{abstract}

Kata Kunci: Pendekatan Pembelajaran Matematika Realistik, Pemecahan Masalah

\section{THE INFLUENCE OF REALISTIC MATHEMATICS EDUCATION TO STUDENTS' PROBLEM SOLVING IN CLASS VII OF SMP 2 SRANDAKAN}

\begin{abstract}
:
The aim of the research was to find out the influence of realistic mathematics education the students' grade 7 toward mathematic problem solving in the class VII SMP Neg. 2 Srandakan. The research was conducted in SMP Neg. 2 Srandakan. The type of the research was experiment with Quasi Eksperimental Design, the research design was Nonequivalent Posttes-Only
\end{abstract}


Control Group Design. The sampling method in the research was simple random sampling. From the six populations class, class VII C was chosen as experimental class which implement realistic mathematics education. Class VII E became control class with direct learning method. Data analysis in this study was divided into two stages, namely the initial stage which is the stage of matching the sample and final stage, which is the stage of data analysis to test the research hypothesis. The normality test result of posttest in experiment class gained sig score $0,088>0,05$ and in the control class gained sig score 0,062 >0,05. Therefore, posttest score in both class in normal distribution. The homogeneity test in posttest gained sig score 0,584 > 0,05 . Therefore the variant both class was homogen. Subsequently, due to prerequisite test fulfilled, T-test was conducted. The result calculation of T-test with Independent-Samples T Tes was sig. 0,003 >0,05. Therefore, it could be concluded that realistic mathematics education approach has influence to students' mathematic problem solving. It could be perceived from the average result of posttestI result in experiment class 77,86 more increasing than control class 69,81 .

Keywords: Realistic Mathematics Education, Problem Solving

How to Cite: Oftiana, S., \& Saefudin, A. A. (2017). Pengaruh Pendekatan Pembelajaran Matematika Realistik Indonesia (PMRI) terhadap Kemampuan Pemecahan Masalah Matematika Siswa Kelas VII SMP Negeri 2 Srandakan. MaPan : Jurnal Matematika dan Pembelajaran, 5(2), 293-301.

\footnotetext{
S alah satu pelajaran wajib yang harus dipelajari seorang siswa adalah matematika. Bahkan matematika diajarkan kepada siswa mulai dari jenjang Sekolah Dasar. Salah satu tujuan pembelajaran matematika menurut Badan Standar Nasional Pendidikan (2006) adalah agar peserta didik memiliki kemampuan pemecahan masalah yang meliputi kemampuan memahami masalah, merancang model matematika, menyelesaikan model dan menafsirkan solusi yang diperoleh. Tujuan tersebut menempatkan pemecahan masalah menjadi bagian dari kurikulum matematika yang penting. Berdasarkan hasil belajar matematika tersebut maka kurikulum dalam pembelajaran matematika sebaiknya mencakup tiga hal, yaitu: konsep, ketrampilan, dan pemecahan masalah.

Guru dituntut untuk mendorong siswa belajar aktif dan dapat meningkatkan pemecahan masalah matematika (Wena, 2011) yang merupakan faktor penting dalam matematika. Slameto (2003: 94) mengemukakan bahwa dalam interaksi di kelas, guru harus banyak memberikan kebebasan kepada siswa, untuk dapat menyelidiki sendiri mengamati sendiri, belajar sendiri dan mencari pemecahan masalah sendiri. Hal ini akan menimbukan tanggung jawab yang besar terhadap apa yang dikerjakan dan kepercayaan terhadap diri
} 
sendiri sehingga siswa tidak selalu menggantungkan diri pada orang lain (Abdurrahman, 2012).

Salah satu pendekatan pembelajaran yang dapat menjadi solusi pembelajaran matematika di SMP Neg. 2 Srandakan adalah pendekatan Pembelajaran Matematika Realistik Indonesia (PMRI). PMRI adalah salah satu pendekatan pembelajaran yang menggunakan konteks dunia nyata dalam proses pembelajaran (Fathurrohman, 2015). PMRI juga merupakan salah satu pendekatan pembelajaran yang inovatif dan memiliki beberapa karakteristik diantaranya yaitu, memberikan kondisi belajar aktif kepada siswa, melibatkan siswa untuk memecahkan suatu masalah dengan cara masing-masing, sehingga siswa dapat mempelajari pengetahuan yang berhubungan dengan masalah tersebut dan sekaligus memiliki keterampilan untuk memecahkan masalah (Fitriana, 2010). Karakteristik PMRI tersebut sangat cocok diterapkan dalam kurikulum 2013 dan untuk meningkatkan kemampuan pemecahan masalah matematika siswa.

Berdasarkan uraian di atas, peneliti berpendapat bahwa diperlukan adanya inovasi pembelajaran sehingga kemampuan pemecahan masalah matematika siswa dapat lebih ditingkatkan. Peneliti juga berpendapat bahwa pendekatan PMRI sangat cocok diterapkan di SMP Neg. 2 Srandakan.

Oleh karena itu, penelitian ini diterapkan di SMP Neg. 2 Srandakan dengan tujuan untuk mengetahui ada tidaknya pengaruh penerapan pendekatan Pembelajaran Matematika Realistik Indonesia (PMRI).

\section{KEMAMPUAN PEMECAHAN MASALAH MATEMATIKA}

Menurut Kamus Besar Bahasa Indonesia (2007), pemecahan berasal dari kata "pecah" yang berarti terbelah menjadi beberapa bagian. Pemecahan sendiri berarti proses, cara, perbuatan memecah atau memecahkan, sementara masalah adalah sesuatu yang harus diselesaikan atau dipecahkan, sehingga pemecahan masalah adalah proses, cara atau perbuatan memecahkan sesuatu yang harus diselesaikan. Sedangkan menurut Dhoruri (2010), memecahkan masalah matematika merupakan proses menerapkan pengetahuan matematika yang telah diperoleh sebelumnya kedalam situasi baru yang belum dikenal.

Menurut Polya (2004), terdapat empat langkah pokok dalam melaksanakan pembelajaran pemecahan masalah, yaitu:

a. Memahami masalah 
Memahami masalah adalah kegiatan menuliskan kembali apa yang diketahui dan ditanyakan dalam permasalahan tersebut.

b. Menyusun rencana penyelesaian

Setelah siswa mampu mengidentifikasi permasalahan, siswa diarahkan agar mencari cara yang tepat untuk menyelesaikan masalah tersebut.

c. Melaksanakan rencana penyelesaian

Siswa melaksanakan penyelesaian berdasarkan langkah-langkah ataupun strategi yang telah direncanakan sebelumnya.

d. Memeriksa kembali hasil

Melihat kembali apa yang dikerjakan, apakah sudah sesuai rencana atau belum. Memeriksa kembali apakah hasil atau metode tersebut dapat digunakan untuk memecahkan permasalahan yang lain atau tidak. Kemudian membuat kesimpulan.

Beberapa strategi yang sering digunakan menurut Polya dan Pasmep diantaranya adalah: mencoba-coba, membuat diagram, mencobakan pada soal yang lebih sederhana, membuat tabel, menemukan pola, memecah tujuan, memperhitungkan setiap kemungkinan, berpikir logis, bergerak dari belakang, membuat model matematikanya, serta mengabaikan hal yang tidak mungkin.

\section{PENDEKATAN PEMBELAJARAN MATEMATIKA REALISTIK INDONESIA (PMRI)}

Realistic Mathematic Education (RME) atau Pendidikan Matematika Realistik adalah suatu teori tentang pembelajaran yang salah satu pendekatan pembelajarannya menggunakan konteks dunia nyata dan berdasarkan pengalaman yang telah didapatkan siswa sebagai titik tolak belajar matematika (Diyah, 2007).

Saefudin (2012) menyatakan bahwa prinsip PMRI sama dengan RME meskipun dalam beberapa hal PMRI berbeda dengan RME karena konteks, budaya, sistem sosial dan alamnya berbeda.

Langkah langkah dalam Pembelajaran Matematika Realistik menurut Shoimin (2014) adalah sebagai berikut:

a. Memahami masalah kontekstual

Guru memberikan masalah kontekstual, kemudian siswa diminta untuk memahami masalah tersebut. Guru menjelaskan soal atau masalah dengan memberikan petunjuk seperlunya terhadap bagian-bagian tertentu yang belum dipahami siswa.

b. Menyelesaikan masalah kontekstual 
Siswa secara individual diminta menyelesaikan masalah kontekstual dengan caranya sendiri. Cara pemecahan dan jawaban masalah yang berbeda lebih diutamakan. Pada tahap ini siswa dibimbing untuk menemukan kembali tentang ide atau konsep atau definisi dari soal matematika.

c. Membandingkan dan mendiskusikan jawaban

Siswa diminta untuk membandingkan dan mendiskusikan jawaban mereka dalam kelompok kecil. Setelah itu, hasil dari diskusi itu dibandingkan pada diskusi kelas yang dipimpin oleh guru. Pada tahap ini dapat digunakan siswa untuk berlatih mengemukakan pendapat.

d. Menarik kesimpulan

Berdasarkan hasil diskusi kelompok dan diskusi kelas yang dilakukan, guru mengarahkan siswa untuk menarik kesimpulan tentang konsep, definisi, teorema, prinsip atau prosedur matematika yang terkait dengan masalah kontekstual yang baru diselesaikan.

Berdasarkan uraian di atas, dapat disimpulkan bahwa pendekatan Pembelajaran Matematika Realistik Indonesia (PMRI) adalah pendekatan pembelajaran yang menggunakan situasi nyata dalam setiap proses belajar, sehingga dapat mengembangkan potensi diri siswa dalam memahami dan memecahkan suatu permasalahan dalam matematika.

\section{METODE PENELITIAN}

Penelitian ini adalah penelitian eksperimen dengan menggunakan metode Quasi Eksperimental Design, yaitu dengan memberikan perlakuan yang berbeda pada dua kelas siswa (Arikunto, 2011). Kelas yang pertama diberikan perlakuan dengan pendekatan Pembelajaran Matematika Realistik Indonesia (PMRI) sebagai kelas eksperimen, sedangkan kelas yang kedua dengan pembelajaran langsung sebagai kelas kontrol. Dalam penelitian ini, peneliti menggunakan desain penelitian Nonequivalent Posttes-Only Control Group Design.

Tabel 1. Rancangan Desain Penelitian

\begin{tabular}{ccc}
\hline Kelompok & Perlakuan & Posttes \\
\hline Eksperimen & $\mathrm{X}$ & $\mathrm{O}$ \\
\hline
\end{tabular}




\section{Kontrol}

$\mathrm{O}$

Keterangan:

$\mathrm{X}$ : Perlakuan yang diberikan, yaitu menggunakan pendekatan Pembelajaran

Matematika Realistik Indonesia (PMRI)

O: Posttes

Pada tahap analisis data yag didasarkan pada sampel, menggunakan teknik analisis statistik deskriptif dan analisis statistik inferensial. Analisis statistik deskriptif meliputi: mean, median, presentil dalam bentuk analisis angka maupun gambar/grafik. Statistik inferensial yang dipakai yaitu uji normalitas, uji homogenitas, dan pengujian hipotesis.

\section{HASIL DAN PEMBAHASAN}

Pembelajaran yang dilaksanakan di kelas eksperimen dengan menggunakan pendekatan Pembelajaran Matematika Realistik Indonesia (PMRI) dan kelas kontrol dengan pembelajaran langsung, masing-masing selama dua kali pertemuan dan didampingi oleh dua observer. Hasil observasi keterlaksanaan pembelajaran dapat diliat dalam tabel berikut:

Tabel 2. Hasil Observasi Keterlaksanaan Pembelajaran dengan Pendekatan PMRI

\begin{tabular}{cccc}
\hline No & Pembelajaran & Persentase & Kriteria \\
\hline 1. & Pertemuan pertama & $87,50 \%$ & Sangat Baik \\
\hline 2. & Pertemuan kedua & $93,75 \%$ & Sangat Baik \\
\hline & Rata-rata & $90,625 \%$ & Sangat Baik \\
\hline
\end{tabular}

Dengan kriteria:

Tabel 3. Klasifikasi Hasil Observasi Keterlaksanaan Pembelajaran

\begin{tabular}{cc}
\hline Persentase Keterlaksanaan & Klasifikasi \\
\hline $85 \% \leq$ nilai $\leq 100 \%$ & Sangat Baik \\
\hline $70 \%<$ nilai $<85 \%$ & Baik \\
\hline $55 \%<$ nilai $\leq 70 \%$ & Cukup \\
\hline $40 \%<$ nilai $\leq 55 \%$ & Kurang \\
\hline $0 \% \leq$ nilai $\leq 40 \%$ & Gagal \\
\hline
\end{tabular}


Setelah pembelajaran pada kelas eksperimen dan kelas kontrol selesai, selanjutnya dilakukan posttes untuk mengetahui kemampuan pemecahan masalah matematika siswa. Analisis data akhir meliputi uji normalitas, homogenitas dan uji hipotesis.

Pada penelitian ini, analisis uji normalitas menggunakan bantuan software SPSS dengan uji Kolmogorov-Smirnov diketahui bahwa data posttes kelas eksperimen nilai sig. $=0,088>0,05$ sehingga $\mathrm{H}_{0}$ diterima dan data posttes kelas kontrol nilai Sig. $=0,062>0,05$ sehingga $\mathrm{H}_{0}$ diterima. Selanjutnya dapat disimpulkan bahwa kedua kelas tersebut berdistribusi normal.

Uji homogenitas menggunakan uji Levene Statistic dengan bantuan software SPSS, diketahui bahwa nilai sig. 0,584 >0,05, sehingga $\mathrm{H}_{0}$ diterima. Artinya, data posttes kelas eksperimen dan kelas kontrol mmpunyai varians yang sama (homogen).

Uji hipotesis dilakukan untuk mengetahui apakah pendekatan Pembelajaran Matematika Realistik Indonesia (PMRI) berpengaruh terhadap kemampuan pemecahan masalah matematika siswa.

a. Hipotesis

$\mathrm{H}_{0}: \mu_{1}=\mu_{2}$ (Pendekatan Pembelajaran Matematika Realistik Indonesia (PMRI) tidak berpengaruh terhadap kemampuan pemecahan masalah matematika)

$\mathrm{H}_{1}: \mu_{1}>\mu_{2}$ (Pendekatan Pembelajaran Matematika Realistik Indonesia (PMRI) berpengaruh terhadap kemampuan pemecahan masalah matematika)

b. Kriteria Pengujian Hipotesis

$\mathrm{H}_{0}$ diterima jika $t_{\text {hitung }}>\mathrm{t}_{\text {tabel }}$ dengan peluang taraf signifikan 5\% diperoleh dari derajat kebebasan $n_{1}+n_{2}-2$

c. Perhitungan

Perhitungan pada penelitian ini menggunakan bantuan software SPSS dengan uji Independent-Samples $T$ Tes. Berikut ini merupakan hasil yang diperoleh yaitu:

Tabel 4. Hasil Uji Statistik

T-test for Equality of Means

\begin{tabular}{ccc}
\hline $\mathrm{T}$ & Df & Sig. (2-tailed) \\
\hline 3,094 & 52 & 0,003 \\
\hline
\end{tabular}




\begin{tabular}{lll}
\hline 3,092 & 51,549 & 0,003 \\
\hline
\end{tabular}

Berdasarkan tabel 4, menunjukkan bahwa kedua data homogen, sehingga hasil uji t yang dipakai adalah baris pertama yaitu 3,094. Kemudian, menghitung $t_{\text {tabel }}=t_{(\alpha, d k)}=t_{(0,05,52)}=1,67469$. Karena $t_{\text {hitung }}>t_{\text {tabel }}$ yaitu 3,094 $>$ 1,67469, maka dapat disimpulkan bahwa $\mathrm{H}_{0}$ ditolak. Artinya pendekatan Pembelajaran Matematika Realistik Indonesia (PMRI) berpengaruh terhadap kemampuan pemecahan masalah matematika.

d. Kesimpulan

Dari perhitungan di atas dapat disimpulkan bahwa pendekatan Pembelajaran Matematika Realistik Indonesia (PMRI) berpengaruh terhadap kemampuan pemecahan masalah matematika siswa kelas VII C di SMP Neg. 2 Srandakan, sehingga uji hipotesis yang diajukan dalam penelitian ini teruji oleh data bahwa Pendekatan Pembelajaran Matematika Realistik Indonesia (PMRI) berpengaruh terhadap kemampuan pemecahan masalah matematika.

\section{SIMPULAN}

Berdasarkan hasil pembahasan dalam penelitian ini, dapat disimpulkan bahwa pembelajaran dengan menggunakan pendekatan Matematika Realistik Indonesia (PMRI) berpengaruh terhadap kemampuan pemecahan masalah matematika siswa kelas VII C di SMP Negeri 2 Srandakan dengan nilai thitung $>$ tabel yaitu 3,094 >1,67469 dan nilai Sig. 0,003.

\section{DAFTAR PUSTAKA}

Abdurrahman, M. (2012). Anak berkesulitan belajar. Jakarta: PT. Rineka Cipta.

Arikunto, S. (2011). Prosedur penelitian (suatu pendekatan penelitian). Jakarta: PT. Rineka Cipta.

Badan Standar Nasional Pendidikan. (2006). Standar kompetensi dan kompetensi dasar untuk matematika SMP-Mts. Jakarta: BNSP.

Saefudin, A. A. (2012). Pengembangan kemampuan berpikir kreatif siswa dalam pembelajaran matematika dengan pendekatan pendidikan matematika realistik indonesia (PMRI). Yogyakarta: Journal UIN SUKA.

Shoimin, A. (2014). 68 Model pembelajaran inovatif dalam kurikulum 2013. Yogyakarta: Ar-Ruzz Media. 
Dhoruri, A. (2010). Meningkatkan kemampuan pemecahan masalah matematika siswa SMP melalui pembelajaran matematika realistik. Yogyakarta: Journal UNY.

Diyah. (2007). Keefektifan pembelajaran matematika realistik (PMR) pada kemampuan pemecahan masalah matematika siswa Kelas VII SMP. Semarang: Journal UNNES.

Fathurrohman, M. (2015). Model-model pembelajaran inovatif. Yogyakarta: ArRuzz Media.

Fitriana, H. (2010). Pengaruh pendekatan pendidikan matematika realistik terhadap kemampuan pemecahan masalah matematika siswa. Jakarta: Journal UIN Jakarta.

Kamus Besar Bahasa Indonesia. (2007). Jakarta: Balai Pustaka.

Polya, G. (2004). How to solve it (a new aspect of mathematical method). USA: Princeton University Press.

Slameto. (2003). Belajar dan faktor-faktor yang mempengaruhinya. Jakarta: PT. Rineka Cipta.

Wena, M. (2011). Strategi pembelajaran inovatifkontemporer. Jakarta: Bumi Aksara. 